\title{
Microwave Instrument-assisted Acid Hydrolysis plus HPAEC-PAD for Quantitative Glycan Monosaccharide Composition Analysis of Serum/Plasma Samples
}

\section{Yanli He}

Affiliated Hospital of Qingdao University, Qingdao, China

Yiran Zhang

Affiliated Hospital of Qingdao University, Qingdao, China

Lijuan Zhang ( $\square$ zhanglj@qduhospital.cn )

Affiliated Hospital of Qingdao University, Qingdao, China https://orcid.org/0000-0002-4357-6566

\section{Method Article}

Keywords: serum, plasma, glycan, microwave instrument-assisted acid hydrolysis, high performance anion exchange chromatography with pulsed amperometric detection (HPAEC-PAD), monosaccharide compositions

Posted Date: December 23rd, 2020

DOI: https://doi.org/10.21203/rs.3.pex-1291/v1

License: (c) (1) This work is licensed under a Creative Commons Attribution 4.0 International License. Read Full License 


\section{Abstract}

This protocol describes the procedures where our published microwave instrument-assisted acid hydrolysis (MAAH) coupled HPAEC-PAD analysis are optimized for glycan monosaccharide composition analysis of serum/plasma samples. The optimized acid hydrolysis of serum/plasma samples takes only $10 \mathrm{~min}$ and $10 \mu \mathrm{l}$ of acid and $2 \mu \mathrm{l}$ serum/plasma samples. The monosaccharide composition analysis is subsequently accomplished by HPAEC-PAD analysis. Each step of the experimental procedures has been optimized with repeated tests of monosaccharide standards and serum samples. The described workflow takes approximately 70-90 min, up to 48 serum/plasma samples can be analyzed with one HPAEC-PAD instrument per day.

\section{Introduction}

Four major types of human biomolecules include nucleic acids (including DNA and RNA), proteins, lipids and glycans. Unlike RNAs and proteins, glycan biosynthesis has no templates but depends on genes, nutrition, and other environmental factors in time and space[1]. As results, animal glycome is estimated to be $10^{4}$ times larger than the proteome[2-5]. Glycans are abundantly present in blood circulations in patients suffering cancerous and non-cancerous diseases. Thus, glycans are rich source for biomarker discovery. However, nearly all studies of serum glycans as possible disease biomarkers have been focused on resolving complicated glycan structures by complicated glycan preparation procedures plus expensive instrumentations, such as LC-MS[2, 5-7].

Despite there are many different types of glycans [8], all human glycans consist of up to 10 monosaccharides, i.e. sialic acid (SA), N-acetyl galactosamine (GlcNAc), N-acetyl glucosamine (GaINAc), galactose (Gal), mannose (Man), fucose (Fuc), glucose (Glc), xylose (Xyl), glucuronic acid (GlcA), and iduronic acid (Ido A). However, few methods have been developed to quantify glycan contents or monosaccharide compositions in human sera or plasmas.

This protocol was originally developed from the corresponding author's laboratory at Washington University in St. Louis for glucosamine- and galactosamine-based, serum- or animal tissue-derived glycosaminoglycan (GAG) quantification purposes [9-13]. We then discovered that significantly different quantity and compositions of glucosamine and galactosamine are present in the plasmas of human patients suffering lung, breast, and pancreatic cancers, respectively, $[10,14]$. Since the major glycans in human sera/plasmas are N-linked and O-linked glycans instead of GAGs, we subsequently developed a HPLC method that can quantify all other monosaccharides in addition to glucosamine and galactosamine released from serum/plasma glycans simultaneously[15-18] for biomarker development.

Releasing monosaccharides from serum/plasma glycans is the bottleneck of monosaccharide composition analysis $[19,20]$. It is usually conducted in a sealed glass ampoule at $105-120^{\circ} \mathrm{C}$ for $1-6$ $\mathrm{h}[21]$ or in a PicoTag station[10]. To enhance the efficiency of the acid hydrolysis, we previously developed a MAAH coupled HPAEC-PAD analysis for monosaccharide composition analysis of 7 different 
types of polysaccharides[22]. In current study, we optimized the acid hydrolysis condition for releasing glycan monosaccharides from serum/plasma samples and the monosaccharide compositions are then obtained by HPAEC-PAD analysis.

\section{Reagents}

Deionized water (Millipore Mingche Q-Gard system, 18.2 M $\Omega-c m$ (Millipore))

Hydrochloric acid (HCl; Sinopharm Chemical Reagent)

Sodium hydroxide solution ( $\mathrm{NaOH} ; 50 \%$ w/w, Fisher Scientific)

Methanol (chromatographically pure, Millipore)

Glucose (Glc; $99 \%$ purity, Merck)

Mannose (Man; 99\% purity, Merck)

Fucose (Fuc; 99\% purity, Merck)

Galactose (Gal; 99\% purity, Merck)

Glucosamine (GIN; 99\% purity, Merck)

Galactosamine (GalN; 99\% purity, Merck)

\section{REAGENT SETUP}

Sera/plasmas Each serum/plasma sample is stored at $-80^{\circ} \mathrm{C}$ before use.

Monosaccharides standard stock solution $(10 \mathrm{mg} / \mathrm{mL})$ Weigh the correct amount of monosaccharides standard, dissolve in Milli-Q water, aliquot into tubes and store at $-20^{\circ} \mathrm{C}$.

$\mathrm{HCl}(6 \mathrm{M})$ Prepare by careful dilution from concentrated $\mathrm{HCl}$. It can be stored at 20-25 ${ }^{\circ} \mathrm{C}$. CRITICAL When working with concentrated $\mathrm{HCl}$, fume hoods must be used and proper protective measures need to be taken according to all relevant workplace regulations.

$\mathrm{NaOH}(18 \mathrm{mM})$ Dilute $0.936 \mathrm{~mL}$ of sodium hydroxide solution $(50 \% \mathrm{w} / \mathrm{w}$, low carbonate) in $1.0 \mathrm{~L}$ of deionized water. Do not shake. Filter with $0.22 \mu \mathrm{m}$ membrane to remove insoluble impurities. CRITICAL When working with $50 \% \mathrm{w} / \mathrm{w} \mathrm{NaOH}$ solution, fume hoods must be used and proper protective measures need to be taken according to all relevant workplace regulations.

$\mathrm{NaOH}(200 \mathrm{mM}$ ) Dilute $10.4 \mathrm{~mL}$ of sodium hydroxide solution (50\% w/w, low carbonate) in $1.0 \mathrm{~L}$ of deionized water. Do not shake. Filter with $0.22 \mu \mathrm{m}$ membrane to remove insoluble impurities. CRITICAL 
When working with $50 \% \mathrm{w} / \mathrm{w} \mathrm{NaOH}$ solution, fume hoods must be used and proper protective measures need to be taken according to all relevant workplace regulations.

\section{Equipment}

Millipore Mingche Q-Gard system (Millipore)

CEM Discover Hydrolysis (CEM Discover Bio)

Thermo Scientific ${ }^{\text {TM }}$ Dionex ${ }^{\text {TM }}$ ICS-5000 chromatography system consisting of:

- ICS-5000 DP chromatographic pump

- ICS-5000 ED detector

- AS-AP autosampler

- Chromeleon ${ }^{\mathrm{TM}}$ chromatographic work station

Centrivap (RVC2-18HCL, CHRIST)

Supercentrifuge (HERAEUS LABOFUGE 400R Centrifuge冈Thermo Fischer Scientific)

Microcentrifuge (Pico17; Thermo Fischer Scientific)

Vortex shaker (Vortex 2; IKA)

\section{EQUIPEMNT SETUP}

CEM Discover Hydrolysis Microwave Reactor For acid hydrolysis of serum/plasma samples, fill the microwave reaction chamber with nitrogen to replace the air according to the manufacturer's instruction. The parameter setting for the power level of microwave is 100 watts, and the temperature is set at $100{ }^{\circ} \mathrm{C}$, and the microwaving time is set for 10 min, respectively.

HPAEC-PAD system With the ability to analyze samples at capillary, microbore, or standard flow rates (or any combination of two, in a dual system) at up to 5000 psi, HPAEC-PAD is the most adaptable ion exchange chromatography system. Thermo Scientific ${ }^{T M}$ Dionex $^{T M}$ ICS $-5000+$ system uses a $250 \mathrm{~mm}$ chromatographic column consisting of $10 \mu \mathrm{m}$ diameter nonporous beads to improve resolution. As an example, below is a table of the specific setup used in our laboratory on an Thermo Scientific ${ }^{\mathrm{TM}}$ Dionex $^{\mathrm{TM}}$ ICS-5000+ chromatography system.

- Thermo Scientific Dionex Carbo PAC ${ }^{\mathrm{TM}}$ PA10 guard column: $4.0 \mathrm{~mm} \times 50$ mm; Thermo Scientific Dionex, Sunnyvale, CA, USA 
- Thermo Scientific Dionex Carbo PAC ${ }^{\mathrm{TM}}$ PA10 analytical column: $4.0 \mathrm{~mm} \times 250 \mathrm{~mm}$; Thermo Scientific Dionex, Sunnyvale, CA, USA

- Mobile phases: 0-15min, isocratic $18 \mathrm{mM} \mathrm{NaOH}$; 15.1-30 min, $200 \mathrm{mM} \mathrm{NaOH}$

- Detector: Electrochemical detector (P/N 072043), standard glycan quadruple potential waveform

-Working electrode: Gold electrode『P/N 061875囚

- Reference electrode: $\mathrm{Ag} / \mathrm{AgCl}$

- Mode: IntAmp

- Flow rate: $1.0 \mathrm{~mL} / \mathrm{min}$

- Sample injection volume: $10 \mu \mathrm{L}$

- Temperature: $30{ }^{\circ} \mathrm{C}$

- Run time: 30 min

\section{Procedure}

\section{Serum collection. TIMING 50 min for 60 samples}

1. Collecting leftover fasting serum samples after their clinical tests at clinical lab of the hospital.

2. Storage: each serum/plasma sample is divided into 3 aliquots in $1.5 \mathrm{~mL}$ EP tubes and stored at $-80{ }^{\circ} \mathrm{C}$ for further analysis. Serum/plasma samples can be stored at $-80^{\circ} \mathrm{C}$ for more than one year without affecting monosaccharide compositions.

\section{Serum glycan acidolysis. TIMING 10 min for up to 10 samples}

3. Serum samples are thawed on ice and $2 \mu \mathrm{L}$ serum sample is transferred into a sample vial.

4. Add $8 \mu \mathrm{L}$ DI water and $10 \mu \mathrm{L} \mathrm{HCl}(6 \mathrm{M})$ into each sample vial. The final volume is $20 \mu \mathrm{L}$.

CRITICAL STEP Make sure that all are added to the bottom without sticking to the wall and samples are mixed well, which is important for glycan acidolysis.

5. Use CEM Discover Hydrolysis microwave reactor to run acidolysis program, which takes 10 min.

CRITICAL STEP Make sure that nitrogen is filled with the reaction system to replace the air.

\section{Sample transfer. TIMING 10 min for up to 10 samples}


6. Transfer sample into $1.5 \mathrm{ml}$ EP tube, after hydrolysis.

CRITICAL STEP Make sure that the sample is completely transferred out to avoid sample loss.

? TROUBLESHOOTING.

\section{Acid removal. TIMING 30 min for up to 10 samples}

7. Remove $\mathrm{HCl}$ by centrifugal evacuation.

CRITICAL STEP Make sure that $\mathrm{HCl}$ is removed to avoid affecting subsequent analysis.

? TROUBLESHOOTING.

8. Dissolve each sample in $150 \mu \mathrm{L}$ DI water. Centrifuge at $15000 \mathrm{r} / \mathrm{min}$ for $10 \mathrm{~min}$ and transfer supernatant to HPAEC-PAD vials.

CRITICAL STEP Make sure that no particles are picked up.

PAUSE POINT The hydrolyzed monosaccharides can be stored at $4{ }^{\circ} \mathrm{C}$ and analyzed within 3 days.

\section{Monosaccharide standard preparation. TIMING 5 min}

9. Preparation of monosaccharide standards: Firstly, dilute the stock solution of Fuc, GlcN, GalN, Glc, Gal, and Man to $1.0 \mathrm{mg} / \mathrm{mL}$. Then mix the 6 monosaccharide standards together and dilute 2 times. The final range of working standard solution is $0.5 \mathrm{mg} / \mathrm{mL}$ to $0.0005 \mathrm{mg} / \mathrm{mL}$.

CRITICAL STEP Make sure that to prepare monosaccharide standard right before use.

\section{HPAEC-PAD analysis. TIMING 30 min per sample}

10. Tuning of the HPAEC-PAD system. Assure that the HPAEC-PAD is working appropriately according to the manufacturers' recommendations or the standard operating procedure (SOP) of the respective laboratory.

11. Set up the HPAEC-PAD system to analyze the hydrolyzed sample as described above in EQUIPMENT SETUP.

CRITICAL STEP Make sure that the hydrolyzed monosaccharides can be analyzed within 3 days.

Characterization of glycan monosaccharide compositions in serum/plasma samples. TIMING It takes 30 min per sample. Up to 48 samples can be analyzed by one HPAEC-PAD instrument in $24 \mathrm{~h}$.

12. Calculating serum/plasma monosaccharide concentrations is based on the regression equation of the monosaccharide standards. 
? TROUBLESHOOTING.

13. Statistical analysis of serum glycan monosaccharide compositions in different diseases in comparison to the healthy control or to each other.

\section{Troubleshooting}

Troubleshooting advice can be found in following statement》

- Step 6 Problem: Sample loss; Solution: Add $20 \mu \mathrm{L}$ DI water to transfer the remaining sample three times.

- Step 7 Problem: Extra residues in hydrolyzed serum samples; Solution: Add $100 \mu \mathrm{L}$ HPLC-grade methanol to remove the residual $\mathrm{HCl}$ for 3 times by centrifugal evacuation.

- Step 12 Problem 1: Early elution of monosaccharides; Solution: When $\mathrm{NaOH}$ is exposed to air too long, it absorbs $\mathrm{CO}_{2}$ and the $\mathrm{NaHCO}_{3}$ generated affects $\mathrm{pH}$ of eluting solution, which results in early elution of monosaccharides. $\mathrm{NaOH}$ solution should be prepared fresh.

- Step 12 Problem 2: No signal, weak signal or impurity peaks; Solution: Check the concentration of $\mathrm{HCl}$. Serum cannot be fully hydrolyzed if the concentration of $\mathrm{HCl}$ is lower than $6 \mathrm{M}$. Over hydrolyzing samples by using higher than $6 \mathrm{M} \mathrm{HCl}$ could result in weak signal or impurity peaks.

\section{Time Taken}

Steps 1-2, serum collection and storage: $~ 50$ min for 60 samples

Steps 3-5, serum glycan acidolysis: 10 min for 10 samples

Step 6, sample transfer: 10 min for 10 samples

Steps 7-8, acid removal: 30 min for 10 samples

Step 9, monosaccharide standard preparation: 5 min

Steps 10-11, HPAEC-PAD analysis: 30 min per sample

Steps 12-13, our lab is equipped with a Thermo Scientific ${ }^{\mathrm{TM}}$ Dionex $^{\mathrm{TM}}$ ICS-5000+ system and has the capacity of analyzing 48 samples per day.

\section{Anticipated Results}

\section{Methodological investigation}

We published a precise and convenient method for analyzing monosaccharide compositions of 7 different types of polysaccharides by MAAH plus HPAEC-PAD analyses previously[22]. Our ultimate goal 
is to use the microwave-assisted acid hydrolysis for serum/plasma monosaccharide composition analysis.

\section{The effects of microwave power on monosaccharide standards}

To test the effect of microwave power on monosaccharide standards, the established microwave conditions $\left(100 \mathrm{~W}\right.$ at $100^{\circ} \mathrm{C}$ for $10 \mathrm{~min}$ ) without $3 \mathrm{~mol} / \mathrm{L} \mathrm{HCl}$, are applied to $0.1 \mathrm{mg} / \mathrm{ml}$ mixed six monosaccharide standards. The t-test was performed on the A (no-microwave) and B (microwave) groups containing the 6 monosaccharide standards. We found that (Figure 1) there is no significant difference between the two group $(p>0.05)$, indicating that the microwave-power itself has no effect on both physical and chemical properties of each of the monosaccharides in the mixture at the condition of $100 \mathrm{~W}$ at $100^{\circ} \mathrm{C}$ for $10 \mathrm{~min}$.

\section{The effect of $\mathrm{HCl}$ concentrations on serum MAAH}

Since the glycans in the serum/plasma samples are present as thousand different kinds of glycoproteins and glycolipids, which are not pure polysaccahrides as those used in our previous publication [15], we tested the best $\mathrm{HCl}$ concentrations that should be used for microwave-assisted acid hydrolysis of serum/plasma samples.

We first made a serum pool by combining $100 \mu \mathrm{L}$ serum from each of 10 kidney cancer patients. Two $\mu \mathrm{L}$ serum $\times 6$ from the serum pool are taken and 0, 1, 2, 3, 4 and $5 \mathrm{~mol} / \mathrm{L} \mathrm{HCl}$ (final concentration) are used for acid hydrolysis under the condition of $100 \mathrm{~W}$ at $100{ }^{\circ} \mathrm{C}$ for $10 \mathrm{~min}$, respectively. The resulting supernatant at each $\mathrm{HCl}$ concentration is analyzed by HPAEC-PAD. The ion chromatogram is shown in Figure 2a. The experiment is repeated three times. The average peak areas of each monosaccharide obtained from the serum pool is calculated. We found that $4 \mathrm{~mol} / \mathrm{L} \mathrm{HCl}$ produces the highest yield of two basic monosaccharides (GalN and GlcN) but with less neutral monosaccharides (Fuc, Gal, Glc, and Man). In contrast, $2 \mathrm{~mol} / \mathrm{L} \mathrm{HCl}$ only partially releases the two basic monosaccharides (GalN and $\mathrm{GlcN}$ ). We concluded that $3 \mathrm{~mol} / \mathrm{L} \mathrm{HCl}$ keeps a balance in releasing both basic and neutral monosaccharides (Figure 2b).

\section{The best volume of serum/plasma samples required for monosaccharide composition analysis}

In searching for the best volume of serum samples for monosaccharide composition analysis, we made another serum pool by combining $100 \mu \mathrm{L}$ serum from each of 10 uremia patients. In triplicate, 2, 5 or 10 $\mu \mathrm{L}$ sera from the serum pool are used for acid hydrolysis under the condition of $3 \mathrm{~mol} / \mathrm{L} \mathrm{HCl}, 100 \mathrm{~W}$ at $100{ }^{\circ} \mathrm{C}$ for 10 min, respectively. The resulting supernatant is analyzed by HPAEC-PAD. The ion chromatogram of serum monosaccharides of the serum pool is shown in Figure 3a. Under the same acid hydrolysis conditions, we found that the content of monosaccharides is increased with increased amount of sera used but the increase is not linear. We decided to use $2 \mathrm{~mL}$ serum for MAAH coupled HPAEC-PAD analyses for two reasons: 1 . two $\mathrm{mL}$ serum is sufficient for detecting all six monosaccharides; 2 . For 
certain diabetic patients, the glucose peak becomes platooned by hitting the up-limit of PAD detection if 5 $\mu \mathrm{L}$ serum is used.

\section{Repeatability of the optimized MAAH coupled HPAEC-PAD analysis}

We next determined the reproducibility of the optimized condition of $3 \mathrm{~mol} / \mathrm{L} \mathrm{HCl}, 100 \mathrm{~W}$ at $100^{\circ} \mathrm{C}$ for 10 min for monosaccharide composition analysis of $2 \mathrm{ml}$ of serum sample from a kidney cancer patient. Mean value of each monosaccharide retention time ( $\mathrm{min})$, peak area ( $\left.\mathrm{nC}^{*} \mathrm{~min}\right)$ and their RSD are showed, respectively.

\section{Monosaccharide retention time (min) RSD (\%) Peak area (nC*min) RSD (\%)}

Fuc $4.87 \pm 0.0040 .080 .23 \pm 0.014 .35$

GalN 8.45 $\pm 0.0040 .050 .70 \pm 0.045 .71$

GlcN 10.09 $\pm 0.0040 .0413 .59 \pm 0.745 .44$

Gal $12.16 \pm 0.0040 .031 .85 \pm 0.084 .32$

Glc $13.34 \pm 0.0040 .039 .72 \pm 0.525 .34$

Man $14.81 \pm 0.0050 .032 .26 \pm 0.125 .31$

The data showed that the relative standard deviation (RSD) of retention time is less than $0.1 \%$ and RSD of peak area is less than $6 \%$, demonstrating a good reproducibility of 6 consecutive analysis (Figure 4).

Thus, the optimized method has the characteristics of rapid acid hydrolysis (only 10 min is needed), efficient (10 samples are processed at a time), less acid consumption (only $10 \mu \mathrm{L} 3 \mathrm{~mol} / \mathrm{L} \mathrm{HCl}$ is used for hydrolysis), straight forward (no monosaccharide derivation is needed for detection[25, 26]), and small sample size (only $2 \mathrm{ml}$ of serum/plasma sample is used). In conclusion, an efficient, sensitive, and quick monosaccharide composition analysis of serum/plasma sample is established using MAAH coupled HPAEC-PAD analysis.

\section{References}

1. Varki, A., Biological roles of glycans. Glycobiology, 2017. 27(1): p. 3-49.

2. Cummings, R.D. and J.M. Pierce, The challenge and promise of glycomics. Chem Biol, 2014. 21(1): p. 115 . 
3. Zhang, L., Glycosaminoglycans in development, health and disease. Preface. Prog Mol Biol Transl Sci, 2010. 93: p. xvii-xviii.

4. Schachter, H. and H.H. Freeze, Glycosylation diseases: quo vadis? Biochim Biophys Acta, 2009. 1792(9): p. 925-30.

5. Hart, G.W. and R.J. Copeland, Glycomics hits the big time. Cell, 2010. 143(5): p. 672-6.

6. Bennun, S.V., et al., Systems Glycobiology: Integrating Glycogenomics, Glycoproteomics, Glycomics, and Other 'Omics Data Sets to Characterize Cellular Glycosylation Processes. J Mol Biol, 2016. 428(16): p. 3337-3352.

7. Rojas-Macias, M.A., et al., Towards a standardized bioinformatics infrastructure for $\mathrm{N}$ - and $\mathrm{O}$ glycomics. Nat Commun, 2019. 10(1): p. 3275.

8. Hu, M., et al., Glycan-based biomarkers for diagnosis of cancers and other diseases: Past, present, and future. Prog Mol Biol Transl Sci, 2019. 162: p. 1-24.

9. Frazier, S.B., et al., The Quantification of Glycosaminoglycans: A Comparison of HPLC, Carbazole, and Alcian Blue Methods. Open Glycosci, 2008. 1: p. 31-39.

10. Studelska, D.R., et al., Quantification of glycosaminoglycans by reversed-phase HPLC separation of fluorescent isoindole derivatives. Glycobiology, 2006. 16(1): p. 65-72.

11. McDowell, L.M., et al., Inhibition or activation of Apert syndrome FGFR2 (S252W) signaling by specific glycosaminoglycans. J Biol Chem, 2006. 281(11): p. 6924-30.

12. Studelska, D.R., et al., High affinity glycosaminoglycan and autoantigen interaction explains joint specificity in a mouse model of rheumatoid arthritis. J Biol Chem, 2009. 284(4): p. 2354-62.

13. Lu, H., et al., Glycosaminoglycans in Human and Bovine Serum: Detection of Twenty-Four Heparan Sulfate and Chondroitin Sulfate Motifs Including a Novel Sialic Acid-modified Chondroitin Sulfate Linkage Hexasaccharide. Glycobiol Insights, 2010. 2010(2): p. 13-28.

14. Pan, J., et al., Glycosaminoglycans and activated contact system in cancer patient plasmas. Prog Mol Biol Transl Sci, 2010. 93: p. 473-95.

15. He, Y.L., et al., Optimizing microwave-assisted hydrolysis conditions for monosaccharide composition analyses of different polysaccharides. International Journal of Biological Macromolecules, 2018. 118: p. 327-332.

16. Zhang, L. and Y. Liu, Detection of free mannose and glucose in serum using high performance liquid chromatography US16/618,033, U.P. office, Editor. 2020. 
17. Zhang, L., et al., Application of a method for detecting monosaccharides hydrolyzed from blood samples for cancer detection, S.I.P.O.o.t. P.R.C, Editor. 2015: China. p. 11.

18. Zhang, M., et al., Using a PCR instrument to hydrolyze polysaccharides for monosaccharide composition analyses. Carbohydrate Polymers, 2020. 240: p. 116.

19. Gasilova, E.R., et al., Association of kappa-carrageenan subjected to deep alkaline hydrolysis. Biopolymers, 2018. 109(9): p. e23236.

20. Wang, Q.C., et al., Influences of acidic reaction and hydrolytic conditions on monosaccharide composition analysis of acidic, neutral and basic polysaccharides. Carbohydr Polym, 2016. 143: p. 296300 .

21. Zhu, H., et al., Acidolysis-based component mapping of glycosaminoglycans by reversed-phase highperformance liquid chromatography with off-line electrospray ionization-tandem mass spectrometry: evidence and tags to distinguish different glycosaminoglycans. Anal Biochem, 2014. 465: p. 63-9.

22. Cao, T., et al., Isolation and Characterization of a Chinese Hamster Ovary Heparan Sulfate Cell Mutant Defective in Both Met Receptor Binding and Hepatocyte Growth Factor NK1/Met Signaling. Cell Physiol Biochem, 2018. 48(4): p. 1480-1491.

23. Liu, Y., et al., Novel Systems Biomarker Defines Diabetic Complications. Science, 2020. Submitted.

24. Zhang, M., et al., A Glycan Homeostasis-based Systems Biomarker that Defines Health and Diseases. Science, 2020. Submitted.

25. Zeng, P., et al., Ampule-sealed Acidolysis for Monosaccharide Composition Analysis of Serum or Plasma Samples. Nature protocol exchange, 2020.

26. Zhang, Y., M. Zhang, and L. Zhang, PCR Instrument-assisted Acidolysis for Monosaccharide Composition Analysis of Serum Glycans. Nature protocol exchange, 2020.

\section{Figures}




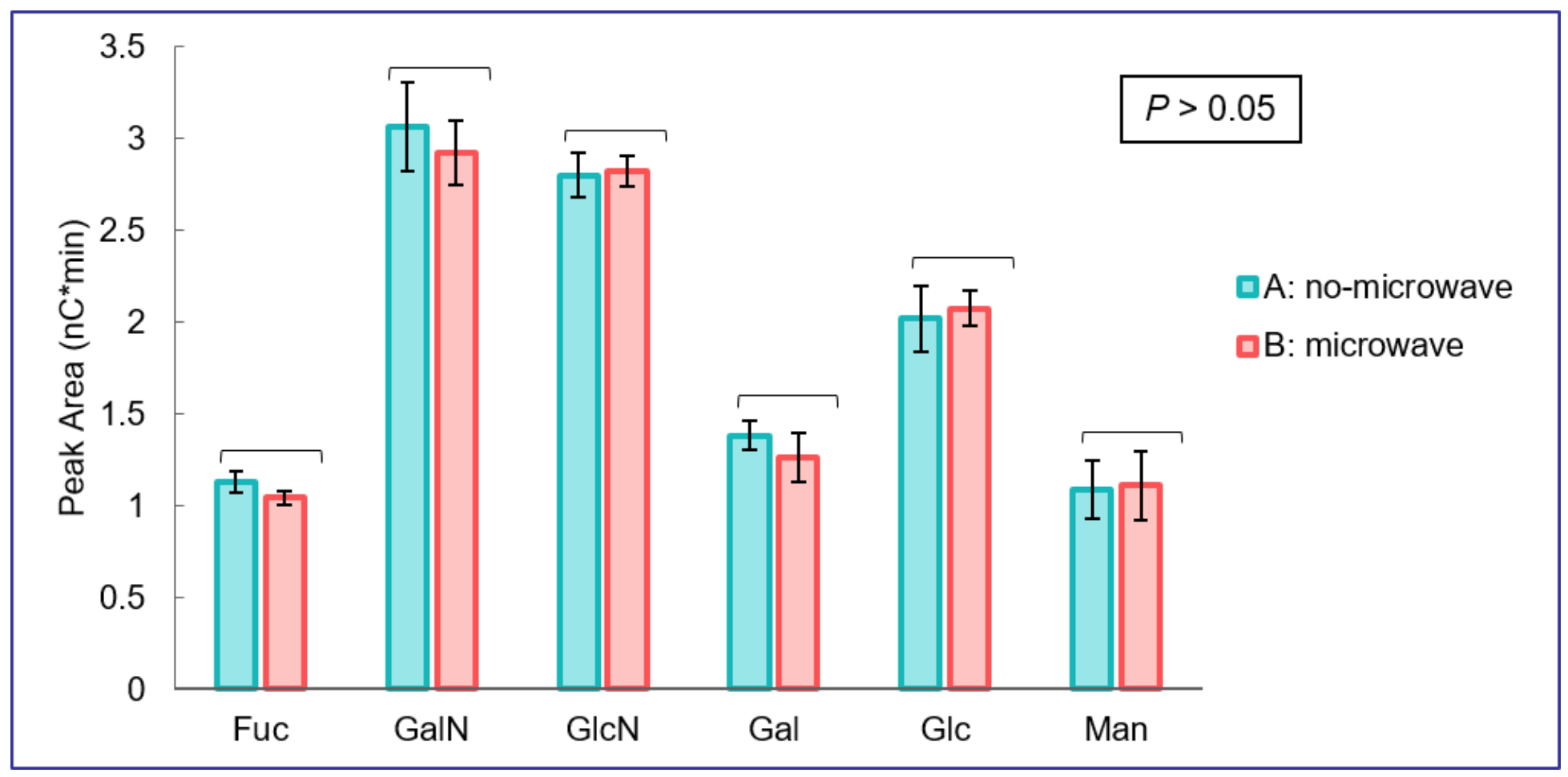

Figure 1

The effect of microwave power on the six monosaccharide standards. 

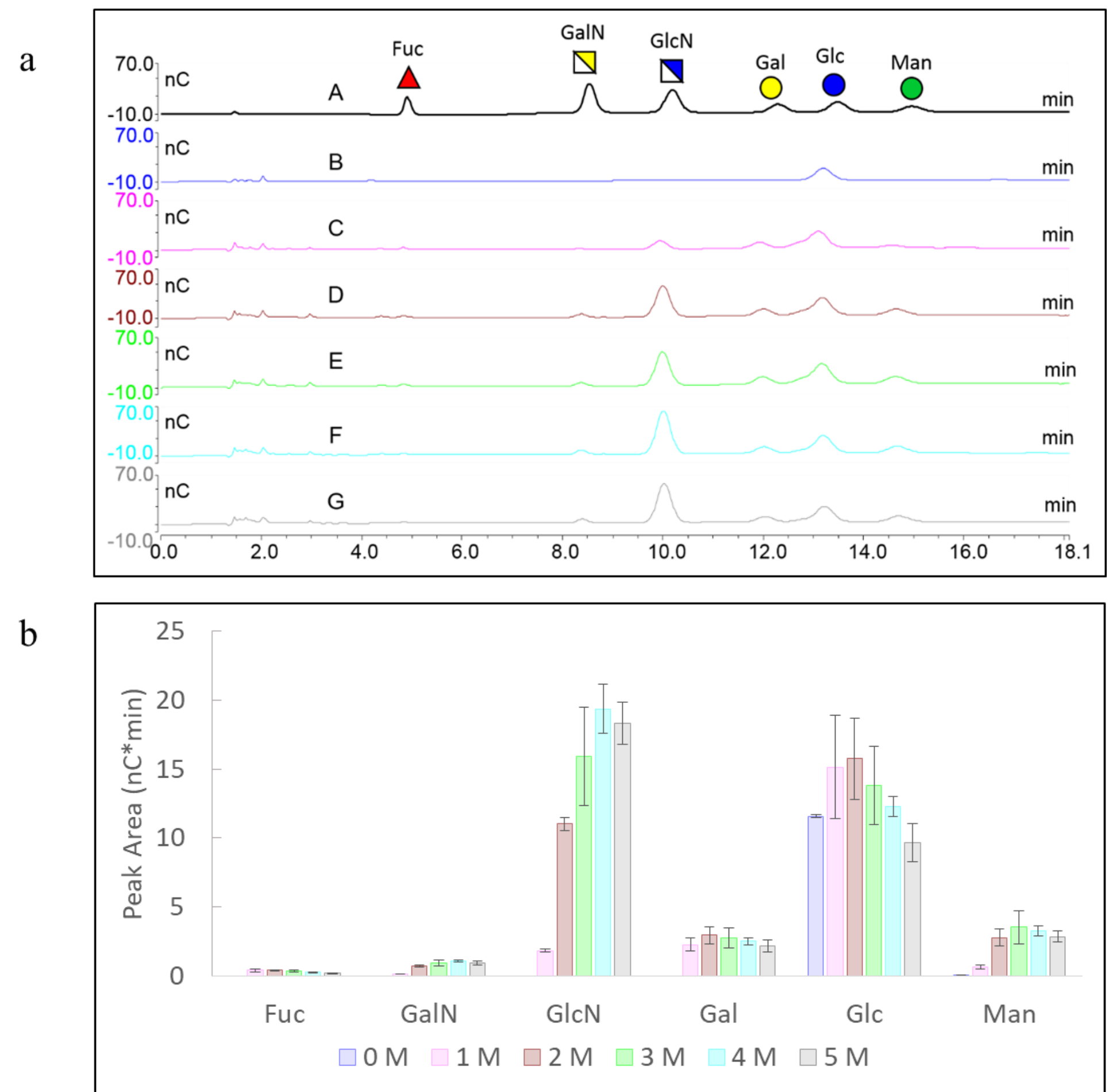

\section{Figure 2}

Figure 2a. The ion chromatograms of monosaccharides from the serum pool of 10 kidney cancer patients by MAAH coupled HPAEC-PAD analysis. (A) $0.005 \mathrm{mg} / \mathrm{mL}$ monosaccharide standard mixture; (B) $0 \mathrm{~mol} / \mathrm{L} \mathrm{HCl}$; (C) $1 \mathrm{~mol} / \mathrm{L} \mathrm{HCl}$; (D) $2 \mathrm{~mol} / \mathrm{L} \mathrm{HCl}$; (E) $3 \mathrm{~mol} / \mathrm{L} \mathrm{HCl}$; (F) $4 \mathrm{~mol} / \mathrm{L} \mathrm{HCl}$ and (G) $5 \mathrm{~mol} / \mathrm{L} \mathrm{HCl}$. Figure $2 \mathrm{~b}$. The peak areas of the six monosaccharides from the serum pool of 10 kidney patients using different concentration of $\mathrm{HCl}$ for microwave-assisted $\mathrm{HCl}$ hydrolysis. Only $\mathrm{Glc}$ and Man are detected in the serum mixture without acid hydrolysis, which are consistent with our previous observation[23, 24]. 
a

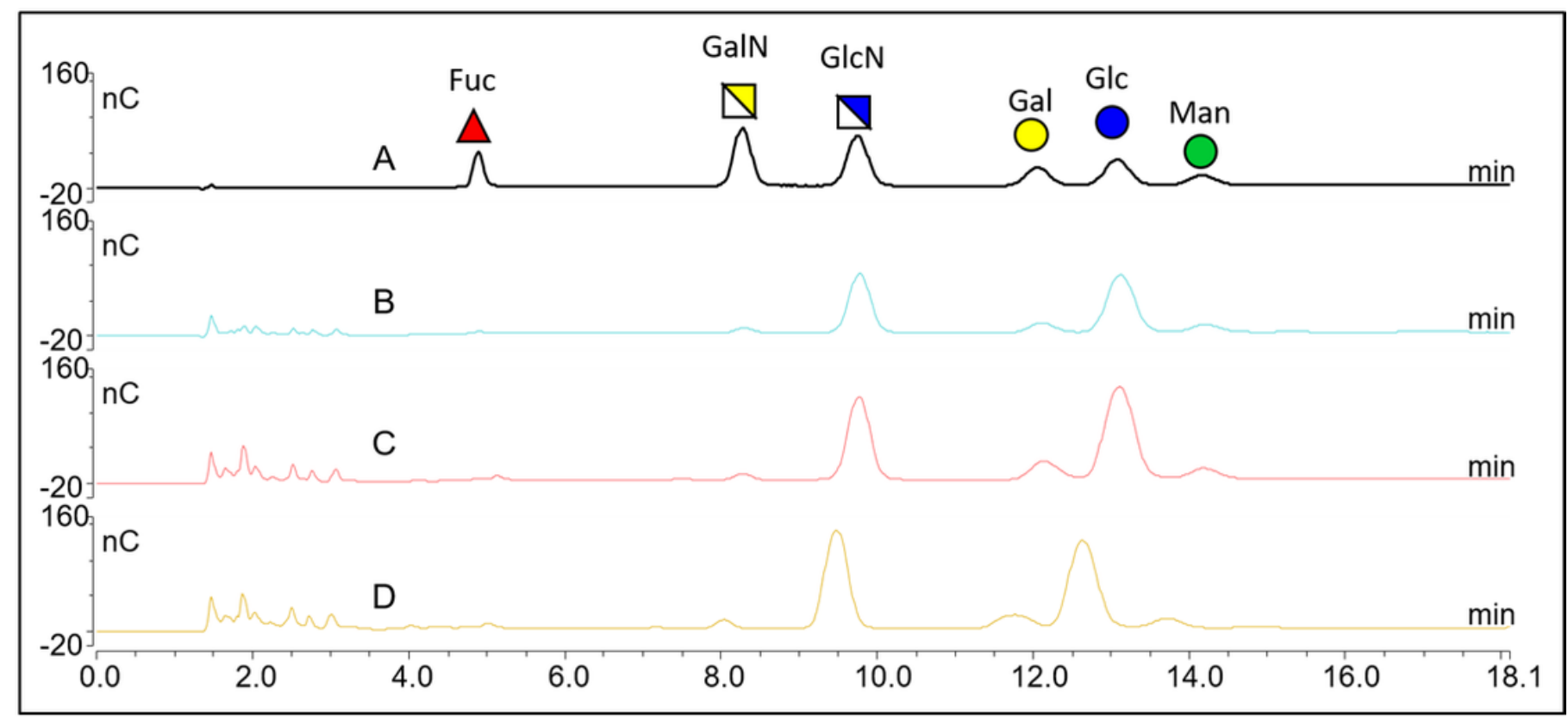

b

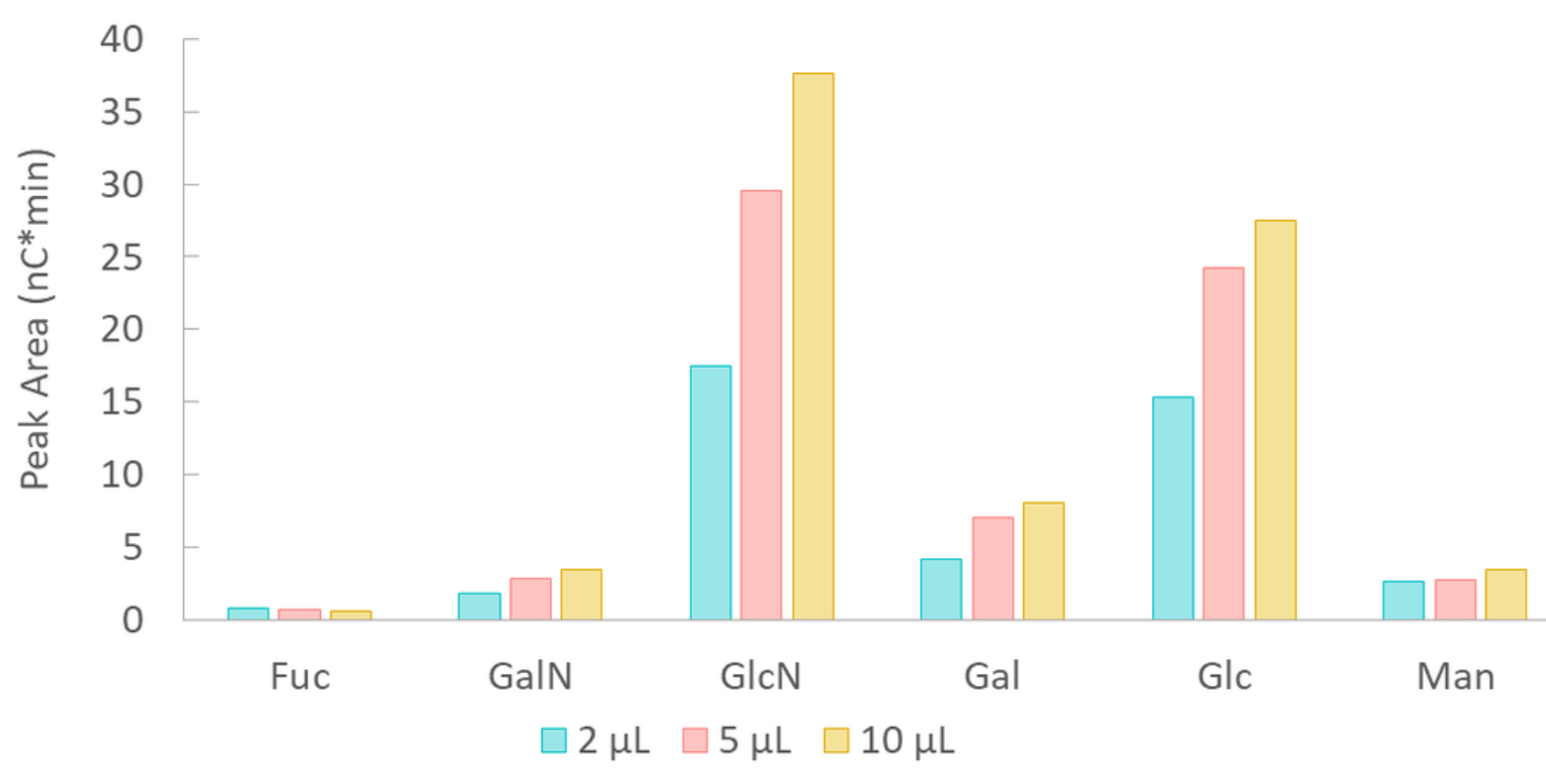

\section{Figure 3}

Figure $3 \mathrm{a}$. The ion chromatograms when 2,5 , or $10 \mu \mathrm{L}$ of the serum from the serum pool of 10 uremia patients is used for MAAH coupled HPAEC-PAD analysis. A $0.01 \mathrm{mg} / \mathrm{mL}$ monosaccharide standard mixture; (B) $2 \mu \mathrm{L}$; (C) $5 \mu \mathrm{L}$ and (D) $10 \mu \mathrm{L}$ serum from the serum pool of 10 uremia patients. Figure $3 \mathrm{~b}$. The peak areas with 2,5 , or $10 \mu \mathrm{L}$ of the serum is used for analysis from the serum pool of 10 uremia patients. 


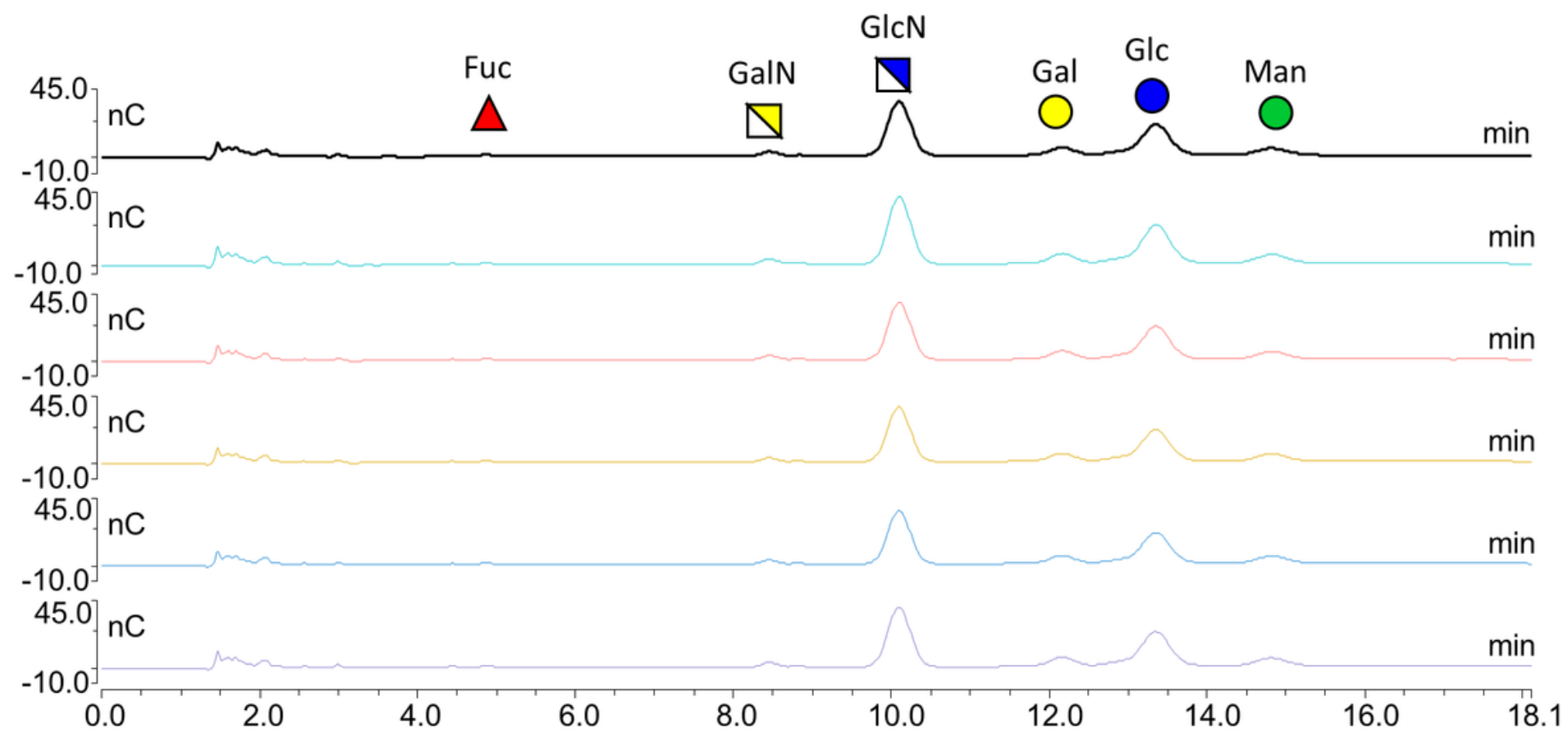

Figure 4

Reproducibility of the method. 